\title{
Multi-Objective Optimization for Industrial Ecology: Design and Optimize Exchange Flows in an Industrial Park
}

\author{
Chao $\mathrm{Gu}$ \\ Laboratoire de Mathematiques Appliquees du Havre \\ (LMAH) \\ Universite du Havre \\ Le Havre, France \\ Lionel Estel \\ Laboratoire de Securite des Procedes Chimiques \\ (LSPC) \\ Institut National des Sciences Appliquees de Rouen \\ (INSA de Rouen) \\ Rouen, France
}

\author{
Adnan Yassine* \\ Laboratoire de Mathematiques Appliquees du Havre \\ (LMAH) \\ Universite du Havre \\ Le Havre, France \\ Sebastien Leveneur \\ Laboratoire de Securite des Procedes Chimiques \\ (LSPC) \\ Institut National des Sciences Appliquees de Rouen \\ (INSA de Rouen) \\ Rouen, France
}

Received: February 10, 2021. Revised: March 5, 2021. Accepted: March 10, 2021. Published: March 26, 2021.

\begin{abstract}
The aim of this project is to find an appropriate mode for green sustainable manufacturing and production. Thus, the concept of this model encourages the development of synergy and leverage of resource networks in order to reduce waste and pollution, and to share resource efficiently. To the best of our knowledge, there is currently no other general mathematical model for designing and optimizing exchange material/energy flows in an industrial park. The purpose of this work is to propose a relative advanced dynamic multi-objective model. Simulations have been performed by using the NIMBUS (Nondifferentiable Interactive Multi-objective Bundle-based optimization System) method. This model can assure a win-win situation for industries and environment.
\end{abstract}

Keywords-modeling; multi-objective optimization; industrial ecology; industrial symbiosis; simulation.

\section{INTRODUCTION}

\section{A. Backgrounds of Le Havre and of this project}

Le Havre is a city located in the north-western of France, which has many manufacturing production firms. In Le Havre region, it concentrates more than a third of French refining capacity. Moreover, it provides about $50 \%$ of production of basic plastics and about $80 \%$ of additives and oils, for the whole France.

The port of Le Havre is the largest container port and the second commercial port in France. Also, it is the fourth port of the Northern Europe.

However, there are more and more pollutions caused by the industries. Thus, the regional authorities of Le Havre have set a target of reducing pollutions, e.g., reducing by $3 \%$ of the $\mathrm{CO}_{2}$ emissions per year from 2012 to 2050 .
Therefore, there are related innovative pilot industrial plants and European research projects that have been installed and launched at Le Havre. Electricity of France (EDF) has developed an innovative research demonstrator in partnership with Alstom and the French Environment and Energy Control Agency (ADEME). On the port industrial area, Sedibex (Veolia) Company operates a plant for the treatment and energy recovery of hazardous waste.

This project is carried out by the Chaire CTSC (Capture, Transport, and Storage of Carbon) in collaboration with the local authorities of Le Havre and with the local important industries.

The aim of this project is to find a green sustainable mode for manufacturing and production. It will be also useful for other manufacturing and production areas.

\section{B. Industiral ecology and Industrial symbiosis}

Industrial ecology is a response for green and sustainable manufacturing.

The notion of industrial ecology was developed in 1989 by Robert Frosh and Nicolas Gallipolis [2]. Broadly speaking, industrial ecology is committed to solve questions related to resource usage in technological societies, with the purpose of evaluating related environmental quality issues and resource availability questions [3].

Industrial symbiosis is a subset of industrial ecology, which has a particular focus on material and energy exchange [4].

Agarwal A. and Strachan P. have said that "Industrial symbiosis can be defined as sharing of services, utility, and byproduct resources among diverse industrial actors in order to add value, reduce costs and improve the environment." 
The first significant experience in the world of industrial ecosystem has emerged in Denmark on the site of Kalundborg since the $1970 \mathrm{~s}$

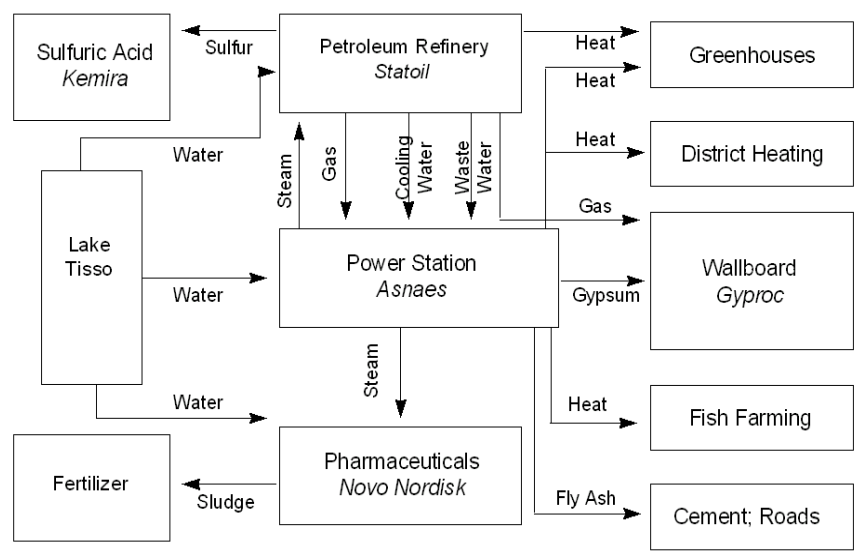

Figure 1. An illustration of the industrial ecosystem of Kalundborg.

In France, actually, there has not been any successful example of industrial ecology.

The first experience of industrial ecology in France was carried out in the industrial area of Grand-Synthe since the year of 2001. In the year of 2007, a study of flows is finally launched. But, until 2011, the next step in formalizing exchanges has not been started yet and it seems to be complicated.

Therefore, Le Havre would like to be the first successful example of ecological industrial park in France.

In the aspect of the theory of industrial ecology, it is generally assumed that industrial symbiosis both generates economic benefits for the industries involved and reduces environmental impact [5].

However, actually, there are few studies that support the assumption of economic and environmental benefits of industrial symbiosis, not even in Kalundborg.

This model can support these two assumptions simultaneously.

To the best of our knowledge, there is no other general mathematical model for designing and optimizing exchange flows in an ecological industrial park. We have proposed a relative steady model [1], in which the storage part was not considered.

In this work, an advanced dynamic model has been proposed with numerical simulations.

In our opinion, the current trend of industrial ecology is to implement more eco-industrial parks in the real life, therefore such models are needed to design and control these potential eco-industrial parks effectively.

\section{Multi-objective optimization}

This model is a multi-objective optimization problem.
Multi-objective optimization problems require simultaneous optimization of several objectives that may compete against each other.

The solution can be seen as optimal when no objective function value can be improved without impairing some other objectives. These optimal solutions are called Pareto optimal solutions [6-7].

The multi-objective optimization problem (MOP) can be formulated as

$$
\begin{aligned}
& \operatorname{minimize}\{\mathrm{fl}(\mathrm{x}), \ldots, \mathrm{fk}(\mathrm{x})\} \\
& \text { subject to } x \in S,
\end{aligned}
$$

where the real-valued objective functions $\mathrm{fl}, \ldots, \mathrm{fk}$ are to be simultaneously optimized with respect to the feasible region $S \subset R^{n}$. If some objective function fi is to be maximized, it is equivalent to minimize $-\mathrm{fi}$. The feasible region identifies the acceptable values for the decision variable vectors $x=\left(x_{1}, \ldots, x_{n}\right)^{T}$ and it is characterized by inequality constraint functions $\mathrm{g} 1, \ldots, \mathrm{gm}$ and lower hand upper bounds $\left(x_{i}^{l}\right.$ and $\left.x_{i}^{u}\right)$ for each decision variable $x_{i}, i=1, \ldots, n$.

Therefore, the feasible region can be defined by

$$
S=\left\{x \in R^{n} / g_{j}(x) \leq 0, j=1, \ldots, m, x_{i}^{l} \leq x_{i} \leq x_{i}^{u}, i=1, \ldots, n .\right\}
$$

Solving problem (1) requires using the methods of multiobjective optimization. In this work, the interactive multiobjective optimization methods are focused.

\section{CONCEPT AND OBJECTIVE}

Generally speaking, this mathematical optimization model was proposed to encourage industrial symbiosis and resource network while assuring the economic gains of all the industries present in an industrial park.

Precisely, the objectives of this model are:

- To maximize the total quantity of exchange flows.

- To maximize the total economic gains of an industrial park.

The concept is shown as in Fig 1.

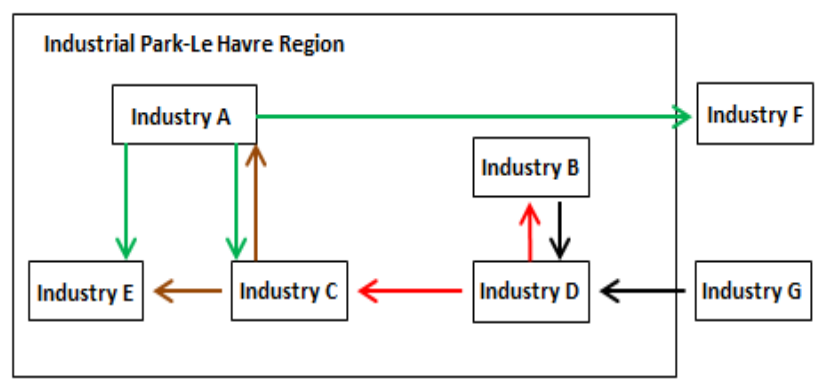

Figure 2. An illustration of our concept, where the arrows represents the exchange flows. The different colors are for the different types of materials/energies. 
This mathematical model takes into account the actual situation of an industrial park and optimizes the exchange flows. It also can study the exchanges flows related with the industries outside the industrial park.

This concept encourages recycling wastes or by-products rather than just throw them away. This model can assure a winwin situation for industries and environment. It means the industries can increase economic gains and improve environmental quality in the same time.

\section{METHODOLOGY AND ASSUMTIONS}

\section{A. Methodology}

It has been mentioned before that this model aims to maximize the total quantity of exchange flows and to maximize the total economic benefits of an industrial park studied while assuring the economic benefit of each industry present in this targeted industrial park.

Firstly, an analysis of the different types of materials'/energies' flows of each industry must be done. Through this analysis, a tensor matrix $\mathrm{S}$ can be figured out and we can have a basic knowledge of the targeted industrial park. The knowledge allows us to figure out clearly the possibilities of exchanges.

Secondly, the parameters used in the expressions will be defined.

Thirdly, for each industry present, there are four parts as listed that need to be formulated:

- Sum E: total sum of the incomes and the expenditures related with the input flows.

- Sum S: total sum of the incomes and the expenditures related with the output flows.

- Production cost: related production cost.

- Delivery cost: delivery cost that the industry has to take in charge.

The input and output flows of every industry will be analyzed in order to formulate the related Income E/S. Several formulas regarding this analysis will be represented for showing the economical earnings related with exchange flows.

The production and the delivery costs will also be considered and be formulated. Thus, we can get a final expression for total income of each industry.

Finally, by including two formulated objective functions, a multi-objective optimization model will be constructed.

\section{B. Assumptions}

For the hypothesis, the model is based on dynamic system. It can be considered the part regarding storage costs and storage management has been included. All costs are expressed in euros. All quantities are expressed in million tons. All distances are expressed in kilometers.

Storage material/energy has been chosen by priority to exchange.
Moreover, we assume that, if we would like to transport a flow from in industry $\mathrm{j}$ to an industry $\mathrm{i}$, this delivery cost can be on a FOB (Free On Board) situation or a CIF (Cost Insurance Freight) situation. It depends on the agreement between these two industries.

The delivery cost includes transport coast and relative insurance cost. Delivery cost is supposed to be linearly proportional to distance and to quantity, excepting some special materials.

TABLE I. DELIVERY SITUATION

\begin{tabular}{|c|c|}
\hline Type of delivery situation & Payer \\
\hline FOB & Buyers \\
\hline CIF & Sellers \\
\hline
\end{tabular}

\section{VARIABLES AND PARAMETERS}

\section{A. Variables}

In this model, the variables are $\left(\phi_{i j}^{k}\right)_{i=1 \ldots N ; j=1 \ldots N ; k=1 \ldots K .}$, which can take real positive values. These variables can be represented by $\psi$. The subscripts i, j, k, N and $\mathrm{K}$ are integers. $\mathrm{N}$ is the amount of industries present in the industrial park studied. $\mathrm{K}$ is the amount of existing types of material/energy.

TABLE II. VARIABLES

The quantity of an inside exchange flow, of a material/energy type named $\mathrm{k}$, from an industry $\mathrm{j}$ to an industry $i$.

The quantity of an inside exchange flow, of a material/energy type named $\mathrm{k}$, from an industry $\mathrm{j}$ to an industry $\mathrm{i}$.

\section{B. Tensoir matrix $S$}

The knowledge, based on the first analysis of types of materials'/energies' flows of every industry, allows us to figure out clearly the exchange possibilities. A tensor matrix, named $\mathrm{S}$, could be used to present the possibilities mathematically. The expression of matrix $\mathrm{S}$ is as shown in (3).

$$
[S]=\left(s_{i j}^{k}\right)_{i=1 \ldots N ; j=1 \ldots N ; k=1 \ldots K} .
$$

TABLE III. MATRIX S

Possibility of a flow, of a material/energy type named $\mathrm{k}$, from an industry $\mathrm{j}$ to an industry $\mathrm{i}$. Binary parameter.

Possibility of a flow, of a material/energy type named $\mathrm{k}$, from an industry $\mathrm{i}$ to an industry $\mathrm{j}$. Binary parameter.

A input flow of an industry $i$, of a material/energy type named ki.

A output flow of an industry $\mathrm{j}$, of a material/energy type named $\mathrm{kj}$. 


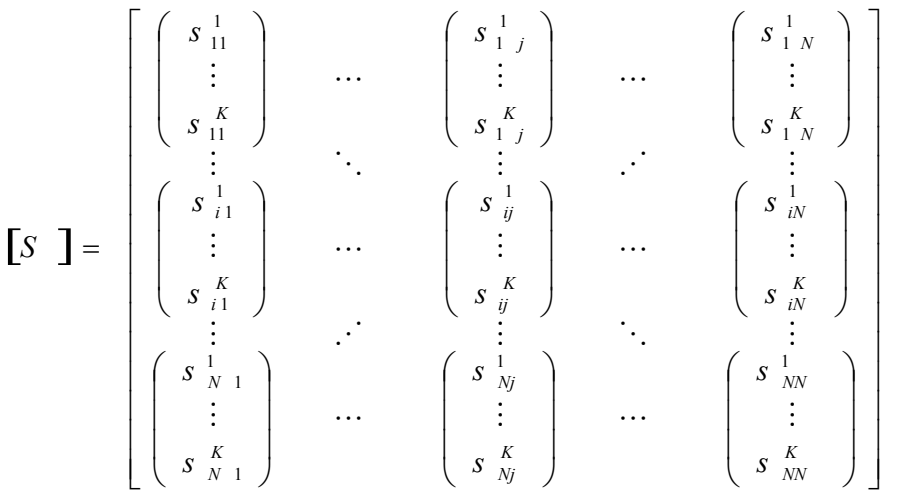

Figure 3. Form of matrix S

If $\mathrm{ki}$ and $\mathrm{kj}$ are the same, then $s_{i j}^{k}$ is equal to 1 . It means that there are possibilities to exchange from an industry $\mathrm{j}$ to an industry $\mathrm{j}$. If not, $s_{i j}^{k}$ is equal to 0 .

\section{Input and output flow's parameters}

For every industry, we have the input and output flows. If an exchange flow is just regarding the industries inside the industrial park, then the flow is characterized as an inside flow. If an exchange flow involves any industry outside the industrial park, then the flow is characterized as an outside flow.

\section{TABLE IV. PARAMETERS USED FOR INPUT FLOWS}

\begin{tabular}{|l|c|}
\hline $\begin{array}{l}\text { The economical index of an inside flow, } \\
\text { which is of a material/energy type named } \mathrm{k}, \\
\text { from an industry } \mathrm{j} \text { to an industry } \mathrm{i} \text {. }\end{array}$ & $I_{i j}^{k}$ \\
\hline $\begin{array}{l}\text { The internal unit cost of a material/energy } \\
\text { type named k for an industry i. }\end{array}$ & $C_{E I i}^{k}$ \\
\hline $\begin{array}{l}\text { The quantity of a material/energy type named } \\
\mathrm{k}, \text { which is needed by an industry i for the } \\
\text { manufacturing. }\end{array}$ & $\phi_{E i}^{k}$ \\
\hline $\begin{array}{l}\text { The external unit cost of a material/energy } \\
\text { type named k for an industry i. }\end{array}$ & $C_{E X i}^{k}$ \\
\hline $\begin{array}{l}\text { The economical index of an outside flow, } \\
\text { which is of a material/energy type named k for } \\
\text { an industry i. }\end{array}$ & $I_{E i}^{k}$ \\
\hline $\begin{array}{l}\text { The quantity of a material/energy type named } \\
\mathrm{k} \text { in the storage of entry of industry } \mathrm{i} \text {. }\end{array}$ & $\phi_{S T M}^{k} E i$ \\
\hline $\begin{array}{l}\text { The quantity of a material/energy type named } \\
\mathrm{k} \text { that will be allowed to remain. }\end{array}$ & $\phi_{S T_{-} E i}^{k}$ \\
\hline $\begin{array}{l}\text { The average of unit storage cost of a } \\
\text { material/energy type named k of an industry i } \\
\text { (resources' storage). }\end{array}$ & $C_{S T_{-} E i}^{k}$ \\
\hline
\end{tabular}

\section{TABLE V. PARAMETERS USED FOR OUTPUT FlOWS}

The economical index of an inside flow, which is of a material/energy type named $\mathrm{k}$, from an industry $\mathrm{i}$ to an industry $\mathrm{j}$.

\begin{tabular}{|l|c|}
\hline $\begin{array}{l}\text { The internal unit cost of a material/energy } \\
\text { type named k for an industry i. }\end{array}$ & $C_{S I i}^{k}$ \\
\hline $\begin{array}{l}\text { The quantity of a material/energy type named } \\
\text { k, which will be produced by an industry i. }\end{array}$ & $\phi_{S i}^{k}$ \\
\hline $\begin{array}{l}\text { The external unit cost of a material/energy } \\
\text { type named k for an industry i. }\end{array}$ & $C_{S X i}^{k}$ \\
\hline $\begin{array}{l}\text { The economical index of an outside flow, } \\
\text { which is of a material/energy type named k for } \\
\text { an industry i. }\end{array}$ & $I_{S i}^{k}$ \\
\hline $\begin{array}{l}\text { The quantity of a material/energy type named } \\
\text { k in the storage of exit of industry i }\end{array}$ & $\phi_{S T M}^{k} S i$ \\
\hline $\begin{array}{l}\text { The quantity of a material/energy type named } \\
\text { k that will be allowed to remain. }\end{array}$ & $\phi_{S T}^{k} S i$ \\
\hline $\begin{array}{l}\text { The average of unit storage cost of a } \\
\text { material/energy type named k of an industry i } \\
\text { (products' storage) }\end{array}$ & $C_{S T_{-} S i}^{k}$ \\
\hline
\end{tabular}

\section{Parameters regarding the delivery and the production}

For transporting a flow from an industry $i$ to industry $j$, of a type named $\mathrm{k}$, a delivery cost must be formulated. Here are the regarding parameters.

\section{TABLE VI. PARAMETERS USED FOR DELEVERY COST}

\begin{tabular}{|l|c|}
\hline $\begin{array}{l}\text { The transport distances between the industry } \mathrm{i} \\
\text { and the industry } \mathrm{j} .\end{array}$ & $r_{i j}$ \\
\hline $\begin{array}{l}\text { The unit transport cost of a certain } \\
\text { material/energy type named k. }\end{array}$ & $C_{\text {unit }}^{k}$ \\
\hline $\begin{array}{l}\text { The index of the total delivery cost for a flow } \\
\text { to transport between two industries i and } \mathrm{j}, \\
\text { which is of a type named k. }\end{array}$ & $I_{\text {delivery-ji }}^{k}$ \\
\hline
\end{tabular}

The parameter $C_{p i}$ has been used for representing the production cost of an industry $i$. It is a constant. It should be noted that the production cost includes all the necessary costs for the manufacturing in except of primary resources costs.

\section{EXPRESSIONS}

\section{A. Expressions regarding Income $E / S$}

The part of the income related with the input and the output flows can be illustrated in Figure 3.

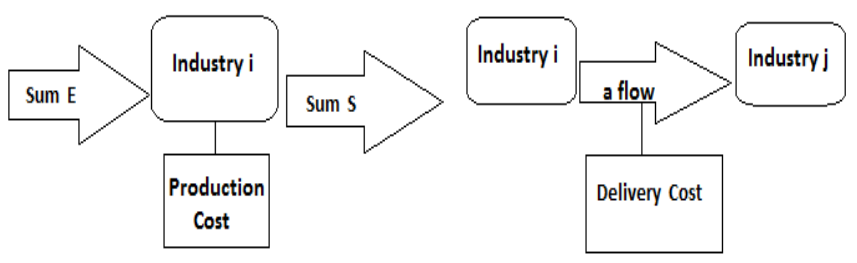

Figure 4. (Left) Illustration of the income related with the input and output flows, as well as the production cost of an industry $i$.

(Right) Illustration of the delivery cost for transporting a flow from an industry $\mathrm{j}$ to an industy $\mathrm{i}$. 
The earnings regarding the input flows of an industry I can be represented as $R_{i E}$. Its expression is shown in (4). It is a sum of incomes and expenditures of each type of materials/energies. For each type, the sum includes three parts:

- $\quad$ Sum related with inside flows (Rinside).

- Sum related with outside flows (Routside).

- Sum related with storage costs (Rstorage).

Similarly, the earnings regarding the output flows of an industry i can be represented as $R_{i S}$ and its expression is shown as (5).

$$
\begin{aligned}
& R_{i E}\left(\phi_{i j}^{k}\right)= \\
& \sum_{k=1}^{K}[(\text { Rinside })+(\text { Routside })-(\text { Rstorage })] \\
& \text { with }\left\{\begin{aligned}
\text { Rinside }= & \sum_{j=1}^{N} s_{i j}^{k} \phi_{i j}^{k} I_{i j}^{k} C_{E I i}^{k} \\
\text { Routside }= & \left(\phi_{E i}^{k}+\phi_{S T M_{-} E i}^{k}-\sum_{j=1}^{N} s_{i j}^{k} \phi_{i j}^{k}-\phi_{S T_{-} E i}^{k}\right) \\
& \times\left(C_{E X i}^{k} I_{E i}^{k}\right) \\
\text { Rstorage }= & \phi_{S T_{-}{ }_{E i}}^{k} C_{S T_{-} E i}^{k}
\end{aligned}\right. \\
& R_{i S}\left(\phi_{j i}^{k}\right)= \\
& \sum_{k=1}^{K}[(\text { Rinside })+(\text { Routside })-(\text { Rstorage })] \\
& \text { with }\left\{\begin{aligned}
\text { Rinside }= & \sum_{j=1}^{N} s_{j i}^{k} \phi_{j i}^{k} I_{j i}^{k} C_{S I i}^{k} \\
\text { Routside }= & \left(\phi_{S i}^{k}+\phi_{S T M}^{k}{ }_{S i}\right. \\
& \left.-\sum_{j=1}^{N} s_{j i}^{k} \phi_{j i}^{k}-\phi_{S T-S i}^{k}\right) \\
& \times\left(C_{S X i}^{k} I_{S i}^{k}\right) \\
\text { Rstorage }= & \phi_{S T}^{k}{ }_{S i} \times C_{S T}^{k}{ }_{S i}^{k}
\end{aligned}\right.
\end{aligned}
$$

\section{B. Expressions regarding production cost and delevery cost}

\section{1) General case}

The production cost has been discussed in section IV.

The notion $C_{T j i}^{k}$ is considered as the actual total transport cost of an exchange flow from an industry $i$ to industry $j$, of a material/energy type named $\mathrm{k}$. Here is its expression.

$$
C_{T j i}^{k}\left(\phi_{j i}^{k}\right)=r_{j i} s_{j i}^{k} \phi_{j i}^{k}\left(C_{\text {unit-transport }}^{k}+C_{\text {unit-insurance }}^{k}\right)
$$

Thus, we can have the expression for all the transport costs that an industry i need to take in charge, as in (7). In fact, the delivery cost includes transport cost and insurance cost. The parameters $I_{\text {delivery-ji }}^{k}$ are used for identify the transport situation (FOB or CIF). We have discussed the transport situations in section III.

$$
C_{T i}^{k}\left(\phi_{j i}^{k}\right)=\sum_{j=1}^{N} \sum_{k=1}^{K} I_{\text {delivery }-j i}^{k} C_{T j i}^{k}\left(\phi_{j i}^{k}\right)
$$

\section{2) Special case}

The transport cost is no more linear for some special material and for some special transport mode. Here is an example of transporting a flow of $\mathrm{CO} 2$ by using pipeline.

Duke University has developed a model for generalizing the cost of transporting $\mathrm{CO} 2$ by using pipeline [8]. Here is the expression for the average cost, as shown in (8). For calculating total transport cost, we can multiply this average cost by distance.

$$
\begin{aligned}
& C_{\text {avg-co2-pipeline }}= \\
& \exp \left(-a_{\text {co2-pipeline }}+\frac{b_{\text {co2-pipeline }}}{\phi_{j i}^{k}}-c_{\text {co2-pipeline }} \times \ln \left(\phi_{j i}^{k}\right)\right)
\end{aligned}
$$

Where $a_{\text {co2-pipeline }}, b_{\text {co2-pipeline }}, c_{\text {co2-pipeline }}$ are positive real numbers and $\mathrm{k}$ is for $\mathrm{CO} 2$.

\section{Final expression for total income of an industry $i$}

As shown in section III, the four terms have been formulated. Finally, total income of an industry i, $R_{i}$, can be expressed in (9).

$$
R_{i}(\psi)=R_{i E}\left(\phi_{i j}^{k}\right)+R_{i S}\left(\phi_{j i}^{k}\right)-C_{p i}-C_{T i}\left(\phi_{i j}^{k}\right)
$$

\section{Multi-ObJective Optimization MODEL}

It was mentioned before that this model aims to maximize total quantity of exchange flows (f1) and to maximize total economic benefit of an industrial park (f2).

These two aims can be represented as two objective functions shown in (10). Also the main constrains of this model are in (11) for assuring that all industries present in this industrial park can have economic benefit by participating this industrial park.

$$
\begin{aligned}
& f_{1}=\sum_{i=1}^{N} \sum_{j=1}^{N} \sum_{k=1}^{K} \phi_{i j}^{k} \\
& f_{2}=\sum_{i=1}^{N} R_{i}(\psi) \\
& R_{i}(\psi)>0, \text { fori }=1 \ldots N .
\end{aligned}
$$

Thus, the final multi-objective optimization model is as shown in (12), which includes two objective functions and main constrains.

The upper and lower bounds' constrains are not included because of space.

$$
(P)=\left\{\begin{array}{l}
\max F(\psi)=\left(f_{1}(\psi), f_{2}(\psi)\right) \\
s . c . \\
R_{i}(\psi)>0, \text { fori }=1 \ldots N . \\
\psi=\left(\phi_{i j}^{k}\right)_{i=1 \ldots N, j=1 \ldots N, k=1 \ldots K .} \in \mathfrak{R}^{+}
\end{array}\right.
$$




\section{ALGORITHM AND SimULATIONS}

\section{A. Why NIMBUS}

NIMBUS (Non-differentiable Interactive Multi-objective Bundle-based optimization System) is an interactive method multi-objective optimization method. It is developed by Miettinen K in 1994 and by Miettinen K and Makela MM in 1995-1997. They have a profound research concerning the NIMBUS method and its synchronous approach [9].

NIMBUS method can be applied for solving both linear and nonlinear problems involving both continuous and integervalued variables.

For this reason, this method is capable of solving complicated real-world problems. Thus, it is appropriate to choose NIMBUS method for solving this industrial symbiosis multi-objective optimization model.

Simulations have been done in order to valid this model by using NIMBUS method.

\section{B. NIMBUS method}

NIMBUS method is based on MPB (Multi-objective Proximal Bundle) method. MPB method is a non-preference method for solving multi-objective problems, which is derived by Makela MM in 1993 and by Miettinen K and Makela MM in 1995. It is an extension of single-objective bundle-based methods of non-differentiable optimization into the multiobjective case.

In NIMBUS method, it is assumed that [11]:

- Less is preferred to more by the decision maker.

- The objective and the constraint functions are locally Lipschizian.

- The objective functions are bounded (from below) over the feasible region $\mathrm{S}$.

It has to emphasize and to be noted that the core of NIMBUS method is the classification of objective functions [10]. It has more choices of classes than other interactive methods, as STEM (Step Method), STOM (Satisficing TradeOff Method) and RD (Reference Direction Method) [11].

There are five classes of NIMBUS. They are functions fi whose value

- $\quad$ Should be decreased $\left(i \in I^{\prec}\right)$.

- $\quad$ Should be decreased only until some aspiration level $\left(i \in I^{\leq}\right)$.

- Are to be held fixed at the current level for the moment $\left(i \in I^{=}\right)$.

- $\quad$ Are allowed to increase only until some upper bound $\left(i \in I^{\succ}\right)$.

- $\quad$ Are allowed to change freely $\left(i \in I^{\diamond}\right)$.

After the decision maker has classified the objective functions, a sub-problem is formed. There are two types of sub- problem can be formed: vector sub-problem and scalar subproblem.

The scalar sub-problem version has been chosen. Thus, the original multi-objective optimization problem, $\mathrm{P}$, is transformed into a single objective optimization problem accordingly.

According to the classification and the connected information, the single objective sub-problem is formed in (13) [10]:

$$
\begin{aligned}
M I N \max & {\left[w_{i}^{h}\left(f_{i}(x)-z_{i}^{*}\right), w_{j}^{h} \max \left\lfloor f_{i}(x)-z_{j}^{h}, 0\right\rfloor\right.} \\
i \in I^{\prec}, j \in I^{\leq} & \\
\text {Subject to } \quad & f_{i}(x) \leq f_{i}\left(x^{h}\right), i \in I^{\prec} \cup I^{\leq} \cup I^{=} \\
& f_{i}(x) \leq \varepsilon_{i}^{h}, i \in I^{\succ} . \\
& x \in S
\end{aligned}
$$

Where $z_{i}^{*}\left(\right.$ fori $\left.\in I^{\prec}\right)$ are the components of ideal criterion vector and $\mathrm{h}$ is iteration number. $\varepsilon_{i}{ }_{i}^{h}$ and $z_{j}^{h}$ are upper and lower bounds. $w_{i}^{h}$ and $w_{j}^{h}$ are optional weights, summing to one.

\section{Optimality for NIMBUS method}

The followings theorems can be used to guarantee the optimality (Proofs, see [11]):

Theorem1. The solution of the scalar sub-problem is weakly Pareto optimal if the set $I^{\prec}$ is nonempty.

Theorem2. Any Pareto optimal solution can be found with an appropriate classification in the scalar sub-problem.

\section{Algorithm for NIMBUS method}

The shortened NIMBUS Algorithm [10] are as followed:

- 1) Choose an initial guess $x^{0} \in R^{n}$. Set $I^{\prec}=$ $\{1,2, \ldots, \mathrm{k}\}$ and solve (2) to obtain $x^{1}$. Set the iteration counter $\mathrm{h}=1$.

- 2) Ask the decision maker to classify the objective functions at $f\left(x^{h}\right)$ into different classes and to specify upper and lower bounds. Ask also for the optional weights. If a feasible classification is unavailable, go to 9).

- 3) Calculate $\hat{x}^{h}$ by solving 2). If $\hat{x}^{h}=x^{h}$, ask the decision maker whether another classification is desired. If yes, set $x^{h+1}=x^{h}, h=h+1$, and go to 2); if no, go to 9).

- 4) Present $f\left(\bar{x}^{h}\right)$ and $f\left(x^{h}\right)$ to the decision maker. If decision maker wants to see different alternatives between them, set $d^{h}=\hat{x}^{h}-x^{h}$ and go to 6). If the decision maker prefers $f\left(x^{h}\right)$, set $x^{h+1}=x^{h}, h=h+1$ and go to 2 ). 
- 5) If $I^{\prec} \neq 0$, set $x^{h+1}=x^{h}, h=h+1$ and go to 2). Otherwise, set $I^{\prec}=\{1,2, \ldots, \mathrm{k}\}$ and solve 2) to obtain $\breve{x}^{h}$. Set $x^{h+1}=\breve{x}^{h}, h=h+1$ and go to2).

- 6) Ask the decision maker to specify the number of intermediate alternatives $\mathrm{P}$ and calculate $f\left(x^{h}+t_{j} d^{h}\right)$ for $\mathrm{j}=1, \ldots, \mathrm{P}$, where $t_{j}=j /(P+1) \cdot$

- 7) Produce weakly Pareto optimal objective vectors from the vectors above by solving auxiliary problem (14).

- 8) Ask the decision maker to choose the most preferred one among the $\mathrm{P}+2$ alternatives. Denote the corresponding decision vector by $x^{h+1}$ and set $\mathrm{h}=\mathrm{h}+1$. If the decision maker wants to continue, go to 2 ).

- 9) Check the Pareto optimality of $x^{h}$ by solving 4).

Here is the auxiliary problem.

MIN $\max \left[f_{i}(x)-z_{i}\right], i=1, \ldots, k$

Subject to $x \in S$

\section{E. Numerical simulations}

The simulations of two different problems will be illustrated in the following. In these two problems, the objective functions and the constraint functions are both linear functions. Thus, they are both convex problems.

Using the next theorem, the global optimality can be guaranteed (Proof, see [11]):

Theorem3. Let the multi-objective optimization problem be convex. Then every locally Pareto optimal solution is also globally Pareto optimal.

Simulations have been performed by using the platform, WWW-NIMBUS [9-10], developed by University of Jyväskylä, Finland. It is based on the NIMBUS method.

\section{1) Simulation 1}

This is an example simulation of an industrial park including three industries and five material/energy types. We will not detail all the digital data because of space.

TABLE VII. MAIN Digital DATA For SimUlation

\begin{tabular}{|c|c|c|c|c|}
\hline Industry & $\begin{array}{l}\text { Input } \\
\text { Material } \\
\text { Type/Quant } \\
\text { ity/Econom } \\
\text { ical Index }\end{array}$ & $\begin{array}{c}\text { Internal/Exter } \\
\text { nal Exchange } \\
\text { Unit Cost }\end{array}$ & $\begin{array}{c}\text { Output } \\
\text { Material } \\
\text { Type/Quant } \\
\text { ity/Econom } \\
\text { ical Index }\end{array}$ & $\begin{array}{c}\text { Internal/E } \\
\text { xternal } \\
\text { Exchange } \\
\text { Unit Cost }\end{array}$ \\
\hline 1 & $1 / 10 /-1$ & $2 / 4$ & $2 / 8 /+1$ & $8 / 10$ \\
\hline 2 & $2 / 10 /-1$ & $9 / 10$ & $3 / 9 /+1$ & $\mathrm{No} / 20$ \\
\hline 3 & $2 / 10 /-1$ & $8 / 10$ & $1 / 4 /+1$ & $2 / 4$ \\
& $4 / 2 /-1$ & $\mathrm{No} / 2$ & $5 / 6 /+1$ & $\mathrm{No} / 30$ \\
\hline
\end{tabular}

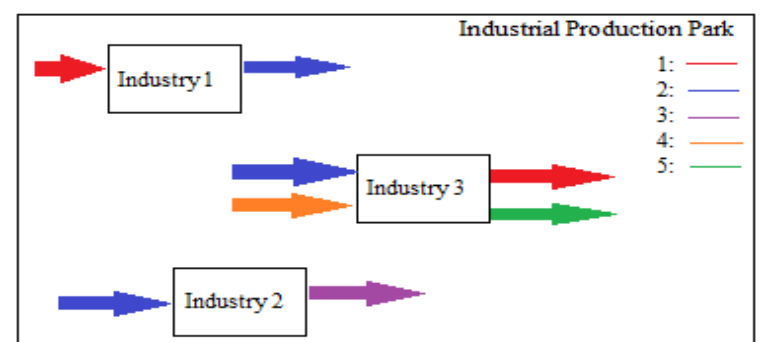

Figure 5. An simplified input/output illustration of the industrial park simulated: the arrows are representing the input and ourput flows and the different colors are for different types of material/energy .

As we can see, the ideal values are 12 (for $\mathrm{fl}$ ) and 450 (for f2). The graph on the left is given when we have more preference on the objective function $\mathrm{fl}$. The graph on the right is given when we have equal preference on both two objective functions.

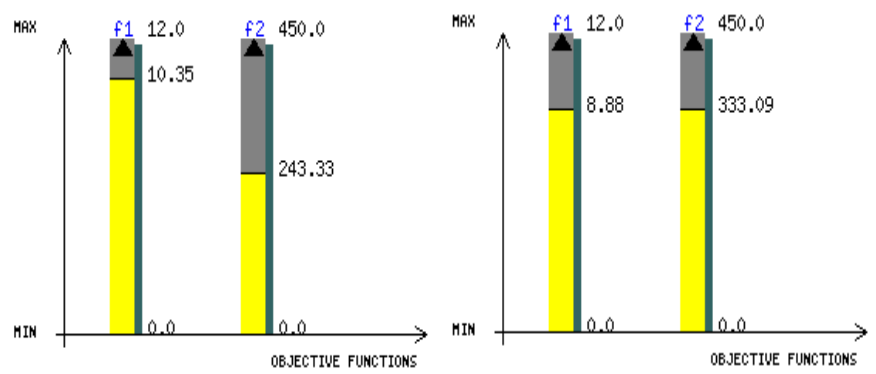

Figure 6. Graphic results of a same problem with different preferences on two objective functions.

\section{2) Simulation2}

This is an example simulation of another industrial production park including nine industries and eleven types of material/energy.

Totally, after the analysis of input/output flows of each industry, there are sixteen potential exchange flows. We will not detail the digital data because of space.

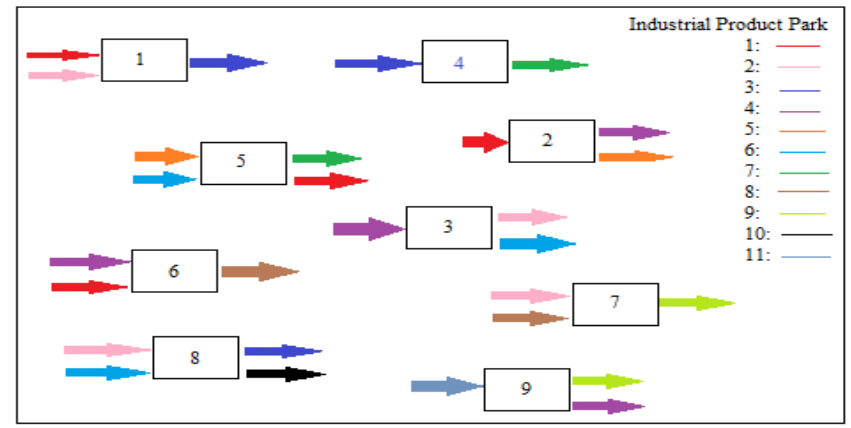

Figure 7. A simplified input/output illustration of the industrial product park simulmated.

The local solver is based on the proximal bundle method. This method can find a locally minimum of a locally Lipschitz continuous function.

The global solver used is based on a genetic algorithm. 
The two functions, $\mathrm{f} 1$ and $\mathrm{f} 2$, are objective functions that have been mentioned in the section VI. The $\mathrm{fl}$ is for the total quantity of implemented exchange flows of a target ecoindustrial park. The $f 2$ is for the total economic benefit of this such park.

The ideal value of $\mathrm{fl}$ is 570 and of $\mathrm{f} 2$ is 9144 . Several tests have been done using the local solver and we got always the same result: $\mathrm{f} 1=231.04$ and $\mathrm{f} 2=3706.34$. VIII.

The results using the global solver are shown in the Table

TABLE VIII. NUMERIAL RESULTS USING THE GLOBAL SOLVER

\begin{tabular}{|l|l|l|l|l|}
\hline $\begin{array}{l}\text { Test } \\
\text { num } \\
\text { ber }\end{array}$ & $\begin{array}{l}\text { Max number of } \\
\text { Generation }\end{array}$ & $\begin{array}{l}\text { Number of last } \\
\text { generations examined }\end{array}$ & f1 & f2 \\
\hline 1 & 10000 & 10000 & 220.86 & 3543.08 \\
\hline 2 & 10000 & 500 & 220.8 & 3542.24 \\
\hline 3 & 10000 & 100 & 215.08 & 3685.79 \\
\hline 4 & 10000 & 50 & 193.02 & 4105.31 \\
\hline 5 & 10000 & 10 & 148.23 & 5446.01 \\
\hline 6 & 10000 & 5 & 135.06 & 5929.33 \\
\hline
\end{tabular}
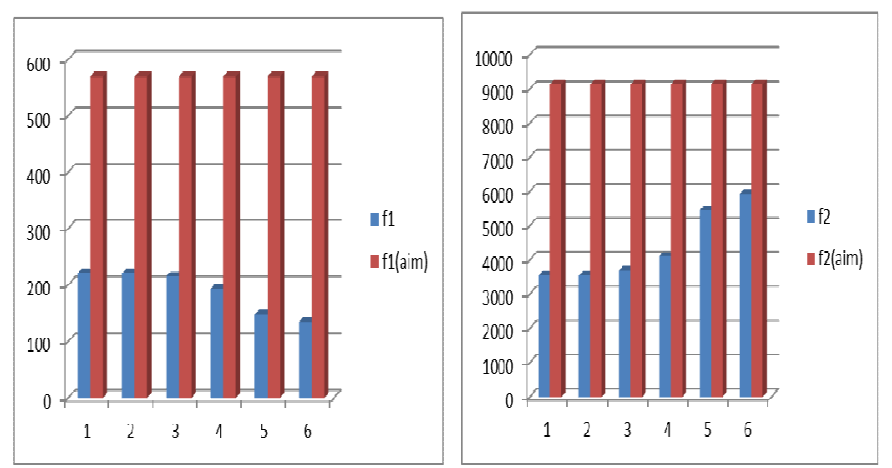

Figure 8. Comparison of the ideal value and the numerical results got during the six tests. (Left) funcfion $\mathrm{f} 1$. (Right) function $\mathrm{f}$.

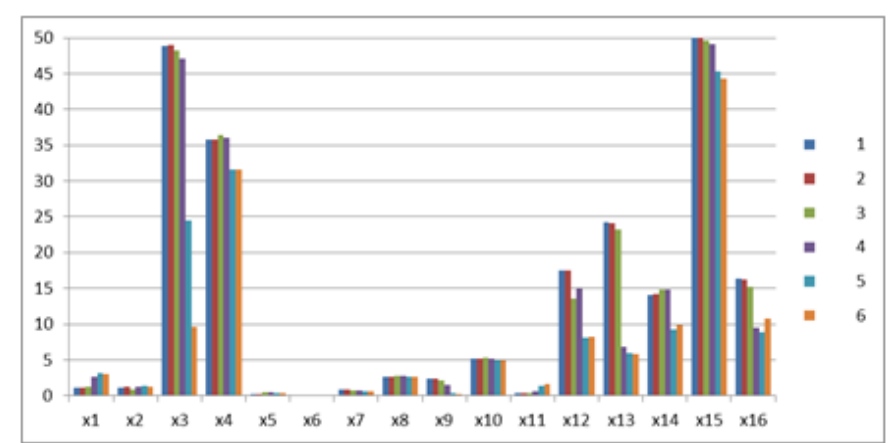

Figure 9. During the six tests, the variation of the sixteen potential exchange flows.

The numerical results of global solver are reliable because they are close to the result of local solver.

\section{CONCLUSIONS AND PERSPECTIVES}

\section{A. Conclusions and Discussions}

A dynamic multi-objective optimization model has been constructed for optimizing exchange flows in an ecological industrial park while assuring economic benefit of each industry present in this park. Using this model, the manufacturing of every industry can be controlled. Also, the negative impact that caused by industries on environment can be decreased.

The NIMBUS method has been used for solving this model and for doing the numerical simulations.

Using this model, the optimization of an industrial park might be failed because one of industries does not have economic benefit, although almost all the other industries could have benefits through the exchanges. This problem is being discussed.

\section{B. Perspectives}

Several aspects will be improved in the near future:

- More expressions of delivery cost will be enhanced to let users more choices.

- More simulations will be performed in order to test the limit of this model and of this method.

\section{ACKNOWLEDGMENT}

This work was financed by the Chair CTSC (http://www.chaire-ctsc.fr/).

\section{REFERENCES}

[1] Gu C, Leveneur S, Lionel E, Yassine A, "Modeling and optimization of material/energy flow echanges in an eco-industrial park", Energy Procedia Journal, 2013, in press.

[2] United Nations. Report of the world commission on environment and development, 1987.

[3] Harper EM, Graedel TE "Industrial ecology: a teenager's progress.", Technology in Society, 2004, Vol.26, pp.433-445.

[4] Agrwal A, Strachan P, "Is Industrial Symbiosis only a concept for developed countries?", The Journal for Waste \& Ressource Management Proffesionals, 2008, Vol.42.

[5] Harper EM, Graedel TE “Industrial ecology: a teenager's progress.", Technology in Society, 2004, Vol.26, pp.433-445.

[6] Heikkola E, Miettinene K, Nieminen P, "Multiobjective optimization of an ultrasonic transducer using NIMBUS", Ultrasonics, 2006, Vol.44, pp.368-380.

[7] Hakanen J, Miettinen K, Sahlstedt K, "Wastewater tratment: New insight provided by interactive multiobjective optimization.", Decision Support Systems, 2011, Vol.51, pp.328-337.

[8] Munish KC, Pratson LF, Williams E, "Potential economies of scale in $\mathrm{CO} 2$ transport through use of a trunk pipeline.", Energy Conversion and Management, 2010, Vol.51, pp. 2825-2834.

[9] Miettinen K, Makela MM, "Synchronous approach in interactive multiobjective optimization.", European Journal of Operational Research, 2006, Vol.170, pp. 909-922.

[10] Miettinen K, Makela MM, "Interactive multiobjective optimization system WWW-NIMBUS on the Internet.", Computers \& Operations Research, 2000, Vol.27, pp.709-723.

[11] Miettinen K, Nonlinear Multiobjective Optimization, Springer Science +Business Media, LLC, 1998.

\section{Creative Commons Attribution License 4.0 (Attribution 4.0 International, CC BY 4.0)}

This article is published under the terms of the Creative Commons Attribution License 4.0

https://creativecommons.org/licenses/by/4.0/deed.en_US 